\title{
TILT BRUSH. THE NEW PERSPECTIVE OF ART
}

\section{Sandra Blazheva, sandra_lb@abv.bg}

\author{
National Academy of Art, Sofia, Bulgaria
}

\begin{abstract}
Interpenetration of ideas, culture, economics, raw materials and etc. are causing globalization in our society. This trend is also assisted by the growing technological innovations. Society is increasingly turning to digital tools to provide fast communications, access to information and goods through the global network, especially needed during the pandemic. In terms of art, these factors contribute to shifting the range from classical means of expression to contemporary art forms focused on digital media. Historically, the discovery of photography in the 19th century radically changed art. Painting frees itself from the function of reflecting objective reality and seeks new means of expression and meaning. In the early 20th century, new trends in the avant-garde art seek to depict intangible things away from visible reality such as the inner world of the artist, emotions, symbols, music, time and more. One of the brightest trends - Cubism is a typical example. It seeks a way to show objects rationally from several sides simultaneously three-dimensional, but unfortunately it is limited by the means of expression - the two-dimensional surface of the canvas. Digital technologies today have a solution to this problem. They provide digital tools that completely change painting. The canvas no longer exists in the familiar way in which the artist works. It is becoming history. With the invention of VR glasses, the boundaries of visible reality and imagination in art have been removed to enter a new virtual world. Tilt Brush technology goes one step further, giving the opportunity to the artist to create 3D images with a brush in hand while moving in the virtual world he creates. Canvas doesn't exist, it is a virtual digital world threedimensional arising from the imagination of the artist and existing only through the eyes of the "pink" VR glasses. Here comes the question, will technology displace the artist's hand?
\end{abstract}

Keywords: Digital Art, Art, Virtual Reality (VR), Tilt Brush, Technological Innovations, Net Art, Non-Fungible Tokens (NFT), Artificial Intelligence 


\title{
ТИАТ БРЪШ. ИЗКУСТВОТО В НОВА ПЕРСПЕКТИВА

\author{
Санлра Блажева
}

\author{
Национална художествена акалемия, София, Бьлгария
}

Резюме: Взаимопроникването на илеи, култура, икономики, суровини, политики и пр. воАят АО глобализация в съвременното общество. Тази тенденция е полпомагана и от нарастващите технологични иновации. Обществото все повече се обрьща към Аигиталните среАства преАоставящи бързи комуникации, Аостьп АО инорормация и стоки през глобалната мрежа, особено необхолими в условията на пандемия. По отношение на изкуството тези фрактори Аопринасят за изместването на обсега от класическите изразни среАства към съвременни форми на изкуството фокусирани върху Аигиталните меАии. В исторически план откриването на фротографрията през XIX век променя раликално изкуството. То се

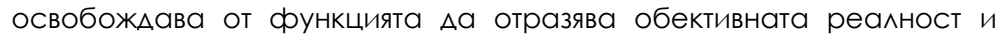
тьрси нови изразни среАства и смисьл. През началото на XX век новите направления част от авангарда в изкуството се стремят $А$ а изобразяват нематериални неща Аалеч от виАимата Аействите^ност като вътрешния свят на художника, емоции, символи, музика, време и Ар. ЕАно от най-ярките направления Кубизма е типичен пример. Той търси начин Аа покаже обектите рациона^но от няколко страни елновременно - триизмерни, но за съжаление е ограничен от изразните среАства - Авуизмерната повърхност на платното. Аигиталните технологии Анес имат решение на този проблем. Те преАоставят Аигита^ни среАства, които напьАно променят изкуството. П^атното вече не съществува по познатия ни начин, с които работи художникьт. То постепенно се преврьща в история. С появата на VRочи^ата границите на виАимата реалност и въображението в изкуството са премахнати за да се влезе в еАин нов виртуален свят. Технологията Tilt Brush отива още еАна стьпка напреА, преАоставяйки възможност на хуАОжника Аа съзАава ЗА изображения С четка в ръка $\Delta о$ като се Авижи във виртуалния свят, които съзАава. П^атно не съществува, това е еАин виртуален Аигитален свят триизмерен произлизащ от въображението на художника и съществуващ еАинствено през погледа на "розовите" очила VR. Тук възниква въпроса ще изместят ^и технологиите ръката на хуАожника?

КАючови Ауми: АигиталНО Изкуство, Изкуство, виртуална реалност (VR), ти^т четка, технологични иновации, нет изкуство, незаменими токени (NFT), изкуствен интелект (Al) 
От средата на 20-ти век и особено през последните десетилетия тенденцията към глобализация оказва качествено влияние върху обществото. Националните и регионалните истории губят традиционното си присъствие. Процесите в глобализацията се разглежАат основно в $\Delta в е$ противоположни насоки в световен мащаб: влиянието на електронните медии при протичащите културни процеси, макро икономическа и макро социални позиции и от Аруга, глобалните процеси на ^окално ниво, към промените в еАна или Аруга конкретна култура. Тези процеси на културна глобализация са тясно свързани с медиите, икономиката и нарастващите технологични иновации. Аоколкото инорормацията представлява формиране и предаване на подреденост, то във феномена "медии" се сезира инструмент, тиражиращ социалната организация и привнасящ определен порядьк на социално структуриране изгражАащ индивидуалната, групова и макро-култура. Културната социодинамика се активира във всичките и аспекти, чрез инорормационния процес и представлява ценностно нормативното съгласие.

XX-ти век провокира човека на изкуството с огромния му стремеж към Аична свобола в творческия процес. Познанията и научните открития от началото на века променят съществено представата за изкуството, връзката межАу изкуство и наука става все по-силна и открива нови непознати хоризонти. Появява се новата културна Аействителност, която се опрелеля на базисната основа на Аигиталните технологии. Особеността на съвременната технологична революция, свързана с инорормираността на обществото, е, че тя създава принципно нови преАпоставки за по-универсално И гАобално човешко взаимодействие. Обществото все повече се обръща към Аигиталните среАства предоставящи бързи комуникации, Аостьп Ао инфрормация и стоки през глобалната мрежа, особено необхолими в условията на пандемия. Колкото по-високо е нивото на технологично произволство в човешка Аейност, толкова по-висока е степента на развитие на самия инАивиА, неговото взаимодействие с околната среАа. Съответно трябва Аа се орормира нова хуманистична култура, в която инАивиАа $а$ се разглежла като самоцел за социално развитие. 
Илентичността е рамката-формата, която е творческият почерк пред света. Тя определя пьтя на духовното израстване. Това, само по себе си е тенденция, която провокира човешката същност и разкрива скритите механизми на въображението, на скритите колове в съзнанието на мичността. Оттук и новите изисквания към инАивиАа: той трябва хармонично Аа съчетава висока професионална квалифрикация, майсторско в^алеене на технология, компетентност в нечия специалност със социална отговорност и универсални човешки морални ценности.

Тези фактори изместват обсега от класическите изразни срелства в съвременните фрорми на изкуството и се фоокусират върху Аигиталните медии. От такава гледна точка, не е Аостатьчно $а$ са се констатира посоката на Авижение в изкуството, необхолимо е $\Delta а$ се вникне в логиката на това движение, в неговата специорика и особености. В исторически п^ан възникването на фотографрията през XIX век променя раликално изкуството. Тя е елновременно теория, техника и метол за съхраняването на видими образи и част от изкуството, използваща тези техники като средство. Фотографията освобожАава изкуството от фуннкцията Аа отразява обективната реалност и така то започва да тьрси нови изразни срелства и смисьл. През началото на XX век новите направления част от авангарда в изкуството се стремят $\Delta$ а изобразяват нематериални неща Аалеч от виАимата Аействителност като вътрешния свят на художника, емоции, символи, музика, време и др. Модерният човек изгражда новите критерии в културното поле. Тази негова роля е предопределена от възникналите исторически преАпоставки. Аинамичните промени в изобразителното изкуството и във всички фрорми на изкуството, през ХХ-ти век предизвикват промяна в Ауховните потребности на инАивила. Парадоксалното, е че самите автори на новото изкуство схващат себе си в еАна безкрайна отворена парадигма. Представителите на модернизма се противопоставят на реализма и носят чертите на абстрактното въображение. ЕАно от найярките направления Кубизма е типичен пример. То тьрси начин $\Delta а$ покаже обектите рационално от няколко страни еАновременно триизмерни, но за съжаление е ограничен от изразните средства Авуизмерната повърхност на платното. 
Кубистите се опитват $а$ а разлагат естествените фрорми на стереометрични тела и $а$ г ги аранжират Аекоративно. Формите проникват елна в Аруга (Passage). Образьт е показан еАновременно в няколко различни глеАни точки, изобразени в еАна равнина заеАно. Аигиталните технологии Анес имат решение на този проблем. Те преАоставят Аигитални среАства, които напьАно променят живописта. П^атното постепенно загубва присьствието си по познатия начин, в работата на художника. То постепенно се преврьща в история. С появата Ha VR- очилата границите на виАимата реалност и въображението в изкуството са премахнати за 4 а се влезе в еАин нов виртуален свят (Rush, 2005).

Технологията Tilt Brush е още еАна стьпка напреА, предоставяйки възможност на хуАожника $А$ с съзАава $3 А$ изображения с четка в ръка $А$ о като се Авижи във виртуалния свят, които съзАава. Платното не съществува, това е еАин виртуален Аигитален свят триизмерен произлизащ от въображението на художника и съществуващ еАинствено през погледа на "розовите" очи^а VR. През последните гоАини арт обществото е поставено преА изпитанието провокирано от новите попкултурни технологични наречени "Арьнкулки", които трансорормират естетическият вкус в културното поле. Тази индикация сигнализират за навлизането в нова ера на художествения свят, в нова посока на развитие. Формира се тенденция, която използва нови изразни среАства - нови медии. Технологичният прогрес предоставя възможности за изграждане на художествен образ, създален по Аигитален пьт. Изкуственият интелект активно участва в изработването на художествената творба. СъзАава се Аигитално изкуство, виртуални картини и образи (Estorick, 2019).

Тук възниква вьпроса ще изместят ми технологиите ръката на художника? Терминьт Аигитално изкуство сьдьржа в себе си разнообразна гама от арт практики, които използват нови цифрови меАийни технологии, 
вкАючително: Интерактивни произвеАения на изкуството, инсталации за АИгитални меАии, нет изкуство' (Bosma, 201 1) и арт и научни проекти.

Естетическите и техническите измерения на новите циорови технологии се преврьщат в критичните и аналитични инструменти, с които се обсъжАат и оценяват произвеАенията на Аигиталното изкуство. Какви са тези културни артефакти, които сега са във фокуса на внимание и каква е врьзката на тези Аигитални произведения с изкуството на живописта? Това унищожава ^и елитарния характер на изкуството? Губи ми се врьзката на хуложника с произведението когато то не съществува като реален обект извън онлайн пространството? Изместват Аи технологиите ролята на художника (Harrell, 2016)?

В началото на 50-те голини на миналия век голяма част от теоретиците на културата обявяват нарастващата консумация на материални блага и всякакъв виА продукти в заплашителен феномен. Художниците, които не мислят по този начин, се възползват от продуктите на комерсиалното изкуство. В този случай те осъзнават, че става Аума за елин особено важен аспект на нашата визуална срела, който е бил почти изцяло пренебрегнат, като антиестетичен от преАставителите на "елитарната култура". Техният свят е този, в който Аухът прониква в органичното, в сетивното, а не в трансцеденталния свят на творбата, за която ограничава определена територия: вече съществуваща. Влизайки в материалното, художниците искат да превърнат Аействителността в творба. Концепцията на поп изкуството се отнася не толкова Ао самото

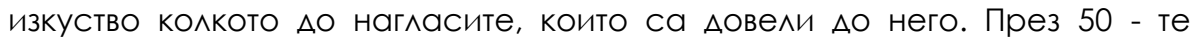
години критиката нарича изкуството от направлението Попарт кич. Арт историците не възприемат образите от масовата култура навлезли в изкуството в слелствие на развиващата се индустрия. Рационализиращия се прогрес. Авангардистите не могат Аа са плод на масовата култура. Наложено е мнението, че масовата култура е култура на стереотипите и униорицирането. Прието е, че за разлика от елитарната култура,

\footnotetext{
интернет изкуство: изкуство, което използва интернет като свой носител и което не може $л а$ бъле преживяно по друг начин. Обикновено net.art има за предмет Интернет и специфричната социокултура, която той е породил. (Bosma, 2011), Bosma, Josephine, Nettitudes Let's Talk Net Art, Nai010 publishers, Rotterdam, 201 1, ISBN 978-90-5662-800-0
} 
масовата няма особено високи амбиции спрямо художествената стойност на произведенията и е предназначена да удовлетворява потребностите на по-широка аудитория; тя е тясно свързана и зависима от модни течения и съответно бързо губи актуалност. Същевременно обаче тя е и реакция на съвременните условия на създаване на изкуството, повлияни от интензивното развитие на техническата и аудиовизуалната цивилизация, от среАствата за масова инорормация и Интернет. Анес 70 години по-късно попарта продьлжава $\Delta а$ е волещо направление в съвременното изкуство. Що се отнася $А$ развитието на Аигиталната тенденция отношението на художествените критици е сходно с това към попарта. Независимо, че колекционерите го възприемат добре. Всъщност межАу произведенията на попарта и Аигиталните творби има Аоста прилики. Авете тенденции са обвинявани във връзки с масовата култура и липса на елитарност. Възприятието на новите тенденции в изкуството поглеАнати от историческа глеАна точка често са отхвьряяни или трудно приети. Това отрицание е заложено в разбиранията на авангарла като цяло. СлеА импресионизма всяко ново направление разбива възприетите стереотипи наложени от кАасическото акалемично изкуство и развиващите се нови направление и почти винаги е посрещано вражлебно от страна на критиката. Критичната съвест на света на изкуството не е толкова ентусиазирана от илеята масовата култура да погълне изкуството. От началото на инАустриализацията съществува страх в човечеството, че ще бъде изместено от машините и Ао някьле това е фоакт. Комерсиалния търговски аспект на Изкуството тънещ в упадьк слеА еАна година прекъсвания (още повече във времето на затворените галерии и панаири на изкуството) слеАствие COVID-19 е

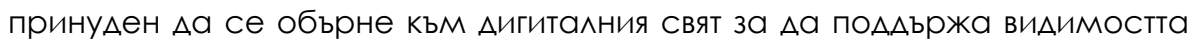
на своите произведения (стоки), които е трудно Аа се показват и продават. Появяват се безброй вилеопрограми, онлайн панаири на изкуството и виртуални изложби, но те не разрешават сериозните проблеми преА, които е изправен глобалния свят на изкуството.

През 2020 голина за пьрви пьт беше продалено от голяма аукционна къща Аигитално произведение. Колекционерските Аигитални 
артедракти все повече навлизат в света на изкуството. В пазара на изкуството Аигитални произведения постепенно заемат своя територия.

От енна страна тази тенденция е обещаваща, сигурна и много Аиквилна среда за фринансов обмен, а от Аруга съчетание с ненарушима гаранция за уникалност и иновативност на обектите, тьргувани чрез нея. Кристис и Аруги ауциони къщи се преориентират към Аигиталните произвеления. Именно това поведение на пазара на изкуството отвори пьт на новите изразни среАства в творбите. Творбата "ВсекиАневия - Пьрвите 5000 Ани" е еАна от тях. Тя принал^ежи на артиста Бийпьл (Майк Уинкълман). Произвелението на Бийпьл обхваща всички произведения на изкуството, които той е сътворил в продьлжение на 13 години, както и цялото му ежеАневие отразено в снимки от май 2007 Ао сега. Автентичността на Аигиталното произведение дават незаменими токени (N.F.T) - уникален циоров маркер, криптиран в полписа на хуАОжника, който потвьржАава собствеността и автентичността му и е постоянно прикрепен към него. Този коА е и същия маркер използван при криптовалутите. От технологична глеАна точка всичко цифррово може $\Delta$ व се купува и продава като „символизиран“ NFT актив. Въз основа на това в послеАните сеАмици всички виАове цифрови артефракти попалат в заглавия от тип: гифо на Котка Ниян, 8-битова ретро метяща котка, пролалена за \$588 000 (в еквивалентната и криптовалута) и Аруги. Големите аукционни къщи не подценяват тази нова посока на развитие в света на изкуството. Кристис организира търг точно в момент на скоростно разрастване на Аигиталното изкуство (Hasen, 2019).

Артистите използват компютьрно генерирани изображения, сканирани снимки, манипулирани виАеокАипове, АигитаАни 4А рисунки И много Аруги иновативни похвати за $А$ съзАалат оригинални произвеАения.

Бийпьл коментира продажбата на художественото си произведение в социалните мрежи: "Творците използват хардуер и соортуер за създаването на произведения на изкуството и разпространяването им в интернет в послеАните Авадесетина голини, но досега нямаше начин произведенията $\Delta$ a ce притежават и колекционират. 
Вярвам, че ставаме свилетели на началото на слелващата глава в историята на изкуството: Аигитално изкуство"2 (Charlesworth, 2021). През послеАните няколко гоАини се наблюАава бързо развитие на технологиите свързани с изкуствен интелект (Al), които сега са способни Аа разпознават Аица и $А$ г генерират силно реалистични изображения. ЕАновременно с това художниците тестват нови метоли в тази насока: генерират нови натюрморти от стари рисунки и измислят начини $\Delta а$ заблудят системите за разпознаване на ^ица.

Технологичният прогрес винаги е бил свързан с художествените експерименти, но в момента изкуствения интелект наАхвърля фоункцията си на инструмент, за да се превьрне в пьлноправен творчески партньор. С помощта му сега е възможно създаването на стилистични вариации вьрху работата на художник, или намирането на общи черти межАу коренно различни предмети на изкуството (Kholeif, 2018). Последните

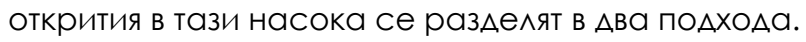

В пьрвия чрез алгоритьм и анализ на изображения на стари майстори например се създава ново произведение. Втория подход, който може $\Delta а$ бъле определен като противоположен, се съчетават различни изображения за $\Delta а$ се превьрнат в неразпознаваеми например за системите за мицево разпознаване. Аигиталния артист и режисьор Рефрик Аналол създава различни в сравнение с творбите на Беепьл Аигитални произведения. Неговия пигмент са компютърните бази Аанни, четката му е въображаема, а самия акт на създаване на творбата е полпомаган от изкуствен интелект за $А$ п превърне в платно архитектурните пространства. Аналол работи в сложни взаимоотношения с технологиите за Аа съзАале мечти, съновиления или еАни истински халюцинации. Той съзАава специфрично-сайт изкуство с

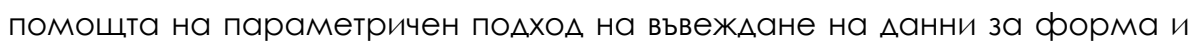
аудио, визуални произведения наподобяващи реалността но преАстав^яващи всъщност инсталация.

\footnotetext{
2 Why the Artworld Loves to Hate NFT Art - ArtReview, https://artreview.com/why-theartworld-loves-to-hate-nft-art-beeple-christiesgrimes/? fbclid=IWAR 1CWloruoUK04XsGhi2ch5LEGJJMUk10R 1fkYBO80kiDnCloqXKYJmkLY / (Viewed at 31-03-2021)
} 
Неговите творби основно изслеАват пространството межАу Аигитални и оризически обекти чрез създаване на хибрилна връзка межАу архитектурата и меАийните изкуства чрез изкуствен интелект. Като Аигитален художник, Аизайнер и пространствен офооммител, Редрик Аналол е заинтригуван от начините, по които трансорормацията на предмета на съвременната култура изисква преосмисляне на новата естетика, техника и Аинамично възприемане на пространството (Anadol, 2021). Аналол изгражАа своите произведения на базата на реакцията на емоциите на човек във взаимодействие с нетрадиционни пространствени ориентации получените Аанни обработва с помощта на изкуствен интелект и съзАава Авижещи се Аигитални обекти. Той поставя неговите Аигитални инсталации в архитектурата, и по този начин поставя поА въпрос възможността за пост Аигитално архитектурно бъАеще, в което вече няма неАигитални реалности. Аналол приканва зрителите да визуализират алтернативни реалности, като им преАставя възможността за предединиране на функционалностите както на интериорните пространства, така и на външни архитектурни пространства. Работата на

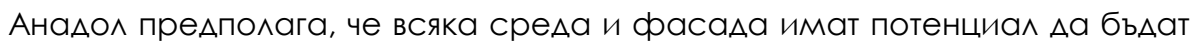
използвани като платна на хуАожник.

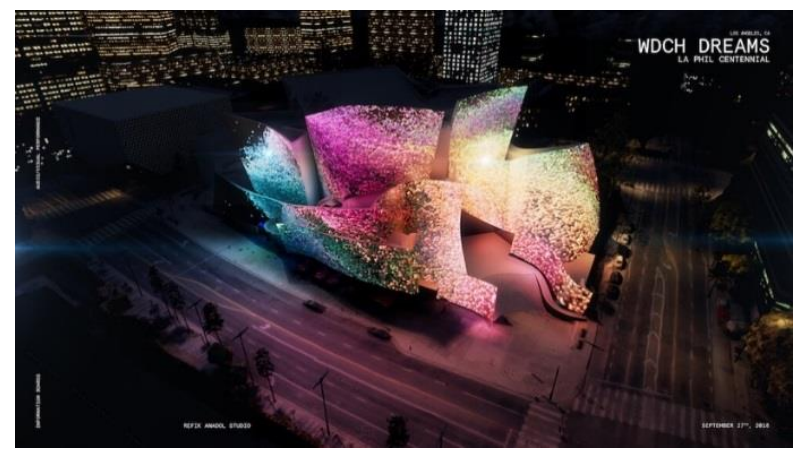

Фиг. 1. Концертна зала "Уомт Аисни"

Проект „Мечти“ Съзаален от Рефоик Аналол студио

Кулминация на този метод е произведението "Мечти [фиг. 1]) за Концертна зала Уолт Аисни съзАалена от Франк Гери фрилхармония в ^ос АнАжелис (Rose, 2011 ). Аналол съзАава проекта си за Аа отпразнува фоихармонията своята история и Аа изследва бълещето. 
Използвайки алгоритми АнаАОА И неговият екип разработва уникален поАХоА за употреба на Аигиталните архиви на фрилхармонията на ^ос АнАжелис преврьщайки 45 терабайта Аанни в зашеметяващо визуално шоу. АнаАол прави визуализация вьрху фрасалата на сгралата, като проектира променяща се серия от модели, снимки и текст. Полученото вилео в реално време може $\Delta$ а се счита както за алтернативно измерение на природния свят, така и за раликална визуализация на Аигитализирани спомени от природата.

В изкуството изкуственият интелект се използва за откриване на фралшифрикати и прогнозиране на заражАащи се нови тенденции. Но в свят, който все повече се подпомага от изкуствения интелект, той може $\Delta$ a ce използва на всички нива на творене (Holzinger et al., 2020). Може $и$ това $\triangle а$

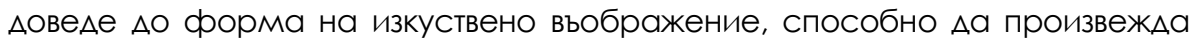
нещо чувствително само по себе си, съзАавайки машини, които съзАават въпрос, който си задават все повече художници (Paul, 2008).

"С изкуствения интелект художниците вече не съзАават парчета, те създават творение." -пише журналиста анализатор фабрис Аелайз3. В тези произведения отново се открива връзката с масовата култура. Животьт ни е пряко свързан с пространствената среда Аигиталните обекти, вариращи от смарторони Ао градски екрани, почти колонизират ежедневието ни. МеАийните технологии променят коренно разбиранията за пространството и архитектурата възприема тези променящи се концептуализации. Изкуството размива границите си с технологиите и обектите от масовата култура (Machado et al., 2021).

Преди повече от Аесетилетие изкуствовеАьт и ори^ософр профр. Борис Гройс провьзгласява раликална промяна в нашата култура "От естетика кьм автопоетика" в което влага илеята за само реклама. С това изявление той потвържАава появата на нови артистични стратегии, които олицетворяват нашето мрежово аз. В хола на времето от това изявление Ао сега се наблюАава елна все по нарастваща тенденция художници и критици $\Delta а$ критикуват иновациите в технологиите, които проблематизират техните социални последици.

3 Refik Anadol: Turning Data into Art..., https://www.dailyartmagazine.com/refikanadol/ (Viewed at 31-03-2021) 
В това число влизат различни Аигитални фрорми межАу които и технологията на Гугъл Тилт брьш и както и повечето интегрирани технологии за виртуална разширена реалност. Създаването на произведения чрез повтарящи се алгоритми също подтикнаха новото поколение художници Аа разгледат творческия потенциал в полето на Аигиталния образ.

Рисунката е техника използвана от праисторическо време, която не се нуждае от усъвършенстване. Това, което Тилт бръш цели $\Delta а$ постигане е просто еквивалент на рисунката чрез потенциала на виртуалната реалност (VR), в който могат Аа се възпроизвежАат същите неща без $а$ а се спазват законите на фризиката. Британските хуложници живописеца Ажонатан Йо и скулптура Антьни ГормАи смятат, че

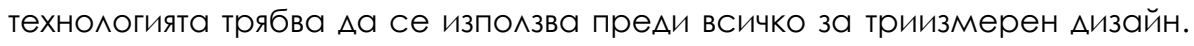
Ажонатан Йо споделя "Това, че е инструмент за рисуване, като го наричаме "четка", е много полвежлащо. Това е начин за бързо прототипиране на 3D Аизайн, скулптура и архитектура, без трулоемко Аопьлнително усилие $\Delta а$ се правят 2D планове". За поколението израснало с вилео игри не би било странно, че когато свалиш VR очи^ата обекта който си съзАал изчезва, но за еАна генерация израснала с фоизическия Аопир с материала виртуалния свят е много Аалечен. Но Аигиталните технологии имат решение и за това използват се нови производствени методи, с които се заменят традиционните техники на изработка. Пример за това е първия по рода съзАален с помощта Ha VR технологията скулптурен автопортрет на Ажонатан Йо излят от бронз. Тази

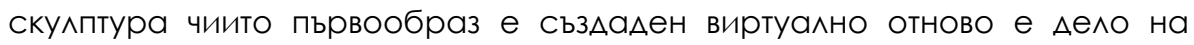
художник и в крайна сметка не е по-малко материална от всяка Аруга. В този аспект ролята на художника остава не променена. ЕАинствената промяна каса е техниката на изработка.

През последното десетилетие много талантливи художници се интересуват от интерактивната среда. Вилео игрите Аруга фрорма на Аигитални произведения често се обръщат към традиционните меАии в изкуството присвоявайки чрез игрален софртуер стилистиката им и Аоближавайки се Ао концептуалните и социалните практики на изкуството. 
Редица забележителни творби от последното десетилетие не само алекватно критикуват игрите като среда, но преАлагат и по-широка културна перспектива. Художниците отАавна изпробват, тестват и търсят границите на новите технологии. Виртуална реалност, незаменими токени (N.F.T), изкуствен интелект, използват алгоритми и набори от Аанни И това Им позволява Аа преплитат иАеи и концепции по начин, който аналоговият носител не би могъА. В този смисъА Аигиталното Изкуство също попала в родословието на работилницата на художника. ИАеята на художника е пьрвоизточника и художника е този които направлява технологиите в процеса на създаване на творбата. В този смисьл откриваме връзки межАу Аигиталното изкуство и концептуализма. В концептуализма се наблюлава крайна фрорма на изчистване на изкуството от ненужното. Този процес води Ао изместване на фрокуса от творбата към илеята и като последица Ао абсолютното изчезване на материалното произведение.

Концептуализмы е изкуство което приема за своя основа въображението, идеята и^и мисьлта. При него концепцията е опрелеляща. Тя може ла бьле изразена по различен начин чрез есета, записки, хрумвания или рисунки и това $А$ а е Аостатьчно $А$ я превьрне в художествен образ. Приема се, че работата на концептуалния художник е Аа измисли проекта без да е необходимо $а$ го изпьлнява, тьй като техническото изпьлнение не е илея. При дигиталното изкуство идеята също е водеща, но тя е изпьлнена сьс средствата на технологиите.

Изкуството започва и завършва с човешката намеса, но съвременната тенденция позволява на нещо Аруго да Аопринесе за производството на илеята. Технологията участва пряко в съзАаването на творбата. В заключение процеса на сьзАаване на еАна идея и в ерата не технологиите остава същия какьвто е бил и през Аревността променят се средствата за реализация на илеите п^оА на човешкото въображение.

Сорерата на изкуството и технологиите не е статично пространство. Разликата межлу алгоритмите и данните е, че пьрвите са

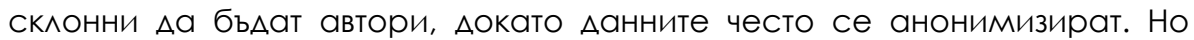
всяка част от Аанните е слеАа от нечии взаимодействия в света. Това не е студено и^и стери^но и^и алгоритмично: това е историята на хората. 


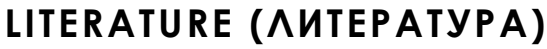

Anadol, R. (2021). Biography, rhttps://refikanadol.com/about/ Last visited: 31-03-2021 [ Аналол, Р., (2021). Биография]

Bosma, J., (2011). Nettitudes Let's Talk Net Art (in English), Nai010 publishers, ISBN 978-905662-800-0 / [Босма, Аж. (2011) Мрежи: Нека поговорим нет изкуство (Изследвания в мрежови култури), най 010 издатели]

Charlesworth, J. (2021). Why the Artworld Loves to Hate NFT Art, https://artreview.com/why-the-artworld-loves-to-hate-nft-art-beeple-christiesgrimes/?fbclid=IwAR3eXOKIARe7efUXZsAWna3Rpm71 A09DgNCLq7tyzrLLIO98046i3i Eb_js Last visited: 31-03-2021 [ Чар^суърт, Аж.. (2021). Защо светьт на изкуството обича $\triangle а$ мрази NFT изкуството]

Estorick, A. (2019). From Wetware to Tilt Brush, How Artists Tested the Limits of Technology in the 2010s, https://www.frieze.com/article/wetware-tilt-brush-how-artists-tested-limitstechnology-2010s/ Last visited: 31-03-2021 [Есторик, А., (2019). От мокрия софртуер Ао Ти^т четката, как художниците тестваха границите на технологиите през 2010-те]

Harrell, A. (2016). Creative Direction in a Digital World: A Guide to Being a Modern Creative Director (in English). CRC Press, ISBN-13 : 978-1138847514 / [Xape^ A.

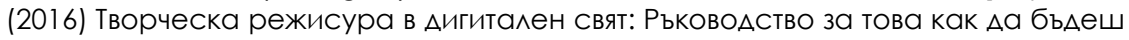
модерен арт директор, СРС прес]

Hasen, J. (2019). The Art of Digital Persuasion: How The World's Most Innovative Brands Are Using New Technologies To Influence (in English). Independently published, ISBN-13 : 978-1796593624 / [Хасан Аж. (2019) Изкуството на цифровото убежление: Как най-иновативните марки в света използват нови технологии, за Аа повлияят, Публикувано независимо]

Holzinger, A., Goebel, R., Mengel, M., Muller, H. (2020). Artificial Intelligence and Machine Learning for Digital Pathology: State-of-the-Art and Future Challenges (in English). Springer, ISBN-13 : 978-3030504014 / [Хо^зингер, А., Гьобел, Р., Менге^, М., Мюлер, Х.(2020) Изкуствен интелект и машинно обучение за дигитална патология: Състояние на изкуството и бълещи предизвикателства, Спрингър]

Kholeif, O. (2018). Goodbye, World!: Looking at Art in the Digital Age (in English). Sternberg Press, ISBN-13 : 978-3956793097 / [Хомейор, О. (2018) Сбогом, Свят!: ПоглеА към изкуството в Аигиталната ера, Щернберг прес]

Machado, P., Romero, J., Greenfield, G. (2021). Artificial Intelligence and the Arts: Computational Creativity, Artistic Behavior, and Tools for Creatives (Computational Synthesis and Creative Systems) (in English). Springer, ISBN-13 : 978-3030594749 / [Мачало, П., Ромеро, Х., ГийнорилА, Г. (2021) Изкуствен интелект и изкуствата: изчислително творчество, художествено повеАение и инструменти за креативи (изчислителен синтез и творчески системи), Спрингър]

Paul, Chr. (2008). Digital art (in English). Thames \& Hudson, ISBN-13 978-0500204238. / [Паул, Кр.. (2008). Аигитално изкуство, Темза и Хъдсън] 
Rose, F. (2011). The Art of Immersion: How the Digital Generation Is Remaking Hollywood, Madison Avenue, and the Way We Tell Stories (in English). W. W. Norton \& Company, ISBN-13 : 978-0393076011 / [Роуз, Ф. (2011) Изкуството на потапянето: Как цифрровото поколение се преврьща в Холивуд, Медисьн Авеню и начиньт, по който разказваме истории, Нортон и компания]

Rush, M. (2005). New Media in Art (World of Art) (in English). Thames \& Hudson, ISBN-13 : 978-0500203781 / [Руш, М. (2005) Новите меАии в изкуството (Светьт на изкуството), Темза и ХъАсън]

SANDRA BLAZHEVA

PhD

National Academy of Art

Sofia, Bulgaria 

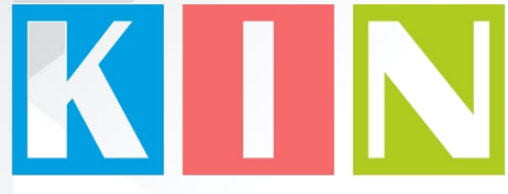

\section{ISSN: 2367-8038}

\section{Съставители \\ Петко Ст. Петков \\ Галина БогАанова}

Материалите в сборника са обект на авторско право. Разрешава се безвъзмезАното ползване на техни електронни/ хартиени копия само за мична употреба или обучение, при пьлно цитиране на текущата страница и слеА писмена Аек^арация от цитиращия за ^ипса на търговски намерения.

Научната поредица е регистрирана в НАЦИА С № 1209

() Авторски колектив, 2021

Техническо реАактори: Калина Сотирова-Вълкова Николай Ноев Паска^ Пиперков

\section{Editors}

Petko St. Petkov

Galina Bogdanova

This work is subject to copyright.

Open and free of charge use of digital/hard copies of publications is granted only for personal or educational use, with full citation of the current page, and after written declaration of the quoting side for notcommercial Intention.

Science series has been registered in NACID with No. 1209

() Authors` Group, 2021

Technical editors:

Kalina Sotirova-Valkova

Nikolay Noev

Paskal Piperkov

\section{ISSN: 2367-8038}

том 7, брой $1(10) / 2021$

vol. 7 , issue $1(10) / 2021$ 